Received: 23 February 2017

Accepted: 17 August 2017

Published online: 12 September 2017

\section{New model for predicting preterm delivery during the second trimester of pregnancy}

\author{
Ya-zhi Zhu ${ }^{1,2}$, Guo-qin Peng ${ }^{3}$, Gui-xiang Tian ${ }^{4}$, Xue-ling $Q u^{5}$ \& Shui-yuan Xiao ${ }^{1}$
}

In this study, a new model for predicting preterm delivery (PD) was proposed. The primary model was constructed using ten selected variables, as previously defined in seventeen different studies. The ability of the model to predict PD was evaluated using the combined measurement from these variables. Therefore, a prospective investigation was performed by enrolling 130 pregnant patients whose gestational ages varied from $17^{+0}$ to $28^{+6}$ weeks. The patients underwent epidemiological surveys and ultrasonographic measurements of their cervixes, and cervicovaginal fluid and serum were collected during a routine speculum examination performed by the managing gynecologist. The results showed eight significant variables were included in the present analysis, and combination of the positive variables indicated an increased probability of PD in pregnant patients. The accuracy for predicting PD were as follows: one positive $-42.9 \%$; two positives $-75.0 \%$; three positives $-81.8 \%$ and four positives $-\mathbf{1 0 0 . 0 \%}$. In particular, the combination of $\geq 2 \times$ positives had the best predictive value, with a relatively high sensitivity $(82.6 \%)$, specificity $(88.1 \%)$ and accuracy rate $(79.2 \%)$, and was considered the cut-off point for predicting PD. In conclusion, the new model provides a useful reference for evaluating the risk of PD in clinical cases.

Preterm delivery (PD) remains a global problem associated with perinatal morbidity, including low birth weight, growth retardation and irreversible damage to the nervous system ${ }^{1}$. The incidence of PD ranges from $5 \%$ to $15 \%$ worldwide, indicating that approximately 15 million preterm babies were born before 37 completed weeks (W) of gestation, which is the second leading cause of perinatal death ${ }^{2}$. In America, 6.14 infant deaths per 1,000 live births and $35.2 \%$ of infant deaths were related to PD in $2010^{3}$. In China, there was a $7.1 \%$ incidence of preterm births, and 7769 preterm births occurred between 28 and $37 \mathrm{~W}$ of pregnancy in $2011^{4}$. In addition, one survey showed an increased mortality associated with PD with an average annual growth rate of $1.52 \%$ since 1996 , accounting for $22.6 \%$ of infant mortality in 2013. Therefore PD is considered the leading cause of infant death ${ }^{5}$.

Approximately thirty years ago, a risk scoring system was proposed for predicting preterm birth, providing a significant reference for further study ${ }^{6}$. To date, many studies have been performed regarding the prediction of preterm birth. Although these studies have resulted in improved prediction of PD and a decrease in the number of premature births, at present, the accuracy of predicting preterm births is still a puzzle because of many factors that contribute to the outcome of PD. These factors include a previous history of PD, gestational age, pregnancy complications, psychological and genetic factors ${ }^{7}$, maternal obesity ${ }^{8,9}$, placenta previa ${ }^{10}$, fat-to-placenta strain ratio value ${ }^{11}$, serum relaxin ${ }^{12}$, insulin-like growth factor-binding protein- $1^{13}$, interleukin-1 $\beta$ (IL- $\left.1 \beta\right)^{14}$, thioredoxin and interleukin 1 receptor antagonist ${ }^{15}$, and fetal fibronectin levels and cervical length measurements ${ }^{16,17}$. However, some of these factors have shortcomings with respect to sensitivity or specificity, which affects the accuracy of PD prediction. Based on previous studies, and seeking to improve the sensitivity and specificity for predicting $\mathrm{PD}$, the present study proposes a new prediction model for premature birth.

\footnotetext{
${ }^{1}$ Department of Social Medicine and Health Management, Xiangya School of Public Health, Central South University, Changsha, 410078, China. 'Department of Medical Affairs, The Second Xiangya Hospital, Central South University, Changsha, Hunan, 410011, China. ${ }^{3}$ Department of Obstetrics and Gynecology, Xiangya Hospital, Central South University, Changsha, Hunan, 410008, China. ${ }^{4}$ Department of ultrasound, The Second Xiangya Hospital, Central South University, Changsha, Hunan, 410011, China. ${ }^{5}$ Department of ultrasound, Weihai municipal hospital, Weihai, Shandong, 264200, China. Correspondence and requests for materials should be addressed to S.-y.X. (email: xiaosy@csu.edu.cn)
} 


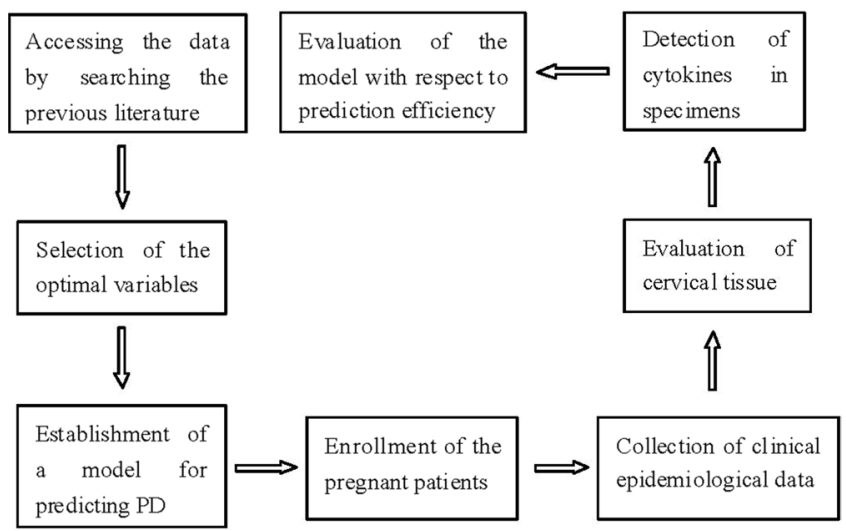

Figure 1. Strategy of constructing and verifying the model.

\begin{tabular}{|l|l|l|l|l|l|}
\hline $\begin{array}{l}\text { Test variables } \\
\text { (units) }\end{array}$ & $\begin{array}{l}\text { Value of } \\
\text { cut-off }^{\mathrm{M}}\end{array}$ & $\begin{array}{l}\text { Sensitivity } \\
(\%)\end{array}$ & $\begin{array}{l}\text { Specificity } \\
(\%)\end{array}$ & PD $^{\mathrm{T}}{ }^{\mathrm{T}}(\mathbf{n})$ & Type of literature \\
\hline $\begin{array}{l}\text { History of preterm } \\
\text { delivery }\end{array}$ & Yes 18, 19 & 51.6 & 78.1 & $15.7(896)$ & $3 \times$ Single center \\
\hline $\begin{array}{l}\text { Prepregnancy } \\
\text { BMI }^{18,20}\left(\mathrm{~kg} / \mathrm{m}^{2}\right)\end{array}$ & $<20$ & 35.6 & 70.0 & $17.5(3333)$ & $\begin{array}{l}1 \times \text { Single center } 1 \times \\
\text { Multicenter }\end{array}$ \\
\hline $\begin{array}{l}\text { Use of tocolytic } \\
\text { agents }\end{array}$
\end{tabular}

Table 1. Variables for predicting preterm delivery in the second trimester of pregnancy. Notes: $n$, the number of sample; $\mathrm{PD} \%$, the percentage of occurring PD; $\mathrm{M}$, the data were shown as the mean level if there was a difference existing in several previous studies; $\mathrm{T}$, the total levels of several single or multicenter studies were evaluated by the corresponding definitions of sensitivity, specificity and PD rate; $\mathrm{S}$, the secondary analysis of the Maternal-Fetal Medicine Units Network or a meta-analysis of the original article. Abbreviations: BMI, body mass index; CL, cervical length; CVF, cervicovaginal fluid; MIF, macrophage migration inhibitory factor; IL-1 $\beta$,

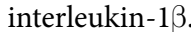

\section{Results}

Selection of test variables. According to the study strategy described in the materials and methods section (Fig. 1), ten variables were selected from the previous seventeen single-center or multicenter studies; these studies provided a large enough sample size for evaluating cut-off values, sensitivity and specificity. These variables were classified as epidemiological indices, cervical characteristics and cytokine level in cervicovaginal fluid or serum. Positive or negative results were judged by the mean cut-off values, indicating an increased risk of PD. In addition, the mean cut-off values, sensitivity and specificity were calculated by evaluating the difference from the original literature. The results of the test variables used in the model are shown in detail in Table 1.

Characteristic of pregnant patients. Of 186 pregnant women enrolled in the study, 56 patients were excluded based on exclusion criteria during pregnancy. Exclusion criteria included triple gestation $(n=2)$, threat of abortion $(n=4)$, serious infection of the genital tract $(n=4)$, pregnancy-induced hypertension $(n=4)$, fetal anomaly $(n=4)$, fetal cytomegalovirus infection $(n=2)$, and 36 patients lost to follow-up due to refuse 


\begin{tabular}{|c|c|c|c|c|}
\hline $\begin{array}{l}\text { Epidemiological } \\
\text { variables (units) }\end{array}$ & $\begin{array}{l}\text { Preterm delivery } \\
<37 \mathrm{~W}(\mathrm{n}=46)\end{array}$ & $\begin{array}{l}\text { Full-term } \\
\text { delivery }(n=84)\end{array}$ & $\begin{array}{l}\text { Statistical } \\
\text { method }\end{array}$ & $\begin{array}{l}P \\
\text { value }\end{array}$ \\
\hline $\begin{array}{l}\text { Maternal age } \\
\text { (years) }\end{array}$ & $30.82 \pm 4.70$ & $29.24 \pm 3.35$ & \multirow{4}{*}{ T test } & 0.654 \\
\hline Parity (times) & $1.75 \pm 0.71$ & $1.32 \pm 0.27$ & & 0.594 \\
\hline $\begin{array}{l}\text { Gestational age } \\
\text { at birth }(\mathrm{W})\end{array}$ & $33.50 \pm 1.82$ & $39.20 \pm 1.05$ & & $0.001^{*}$ \\
\hline Birth weight (g) & $2,573 \pm 741$ & $3,628 \pm 360$ & & $0.004^{*}$ \\
\hline $\begin{array}{l}\text { Ratio of singleton } \\
\text { vs twin gestations }\end{array}$ & $8.2: 1.0$ & 27.0: 1.0 & & 0.203 \\
\hline $\begin{array}{l}\text { Ratio of } \\
\text { nulliparous vs } \\
\text { multiparous }\end{array}$ & $0.77: 1.0$ & 1.4: 1.0 & & 0.105 \\
\hline $\begin{array}{l}{ }^{\mathrm{a}} \text { Cervical surgery } \\
(\%)\end{array}$ & $5(10.9)$ & $6(7.1)$ & \multirow{5}{*}{$\chi^{2}$ test } & 0.465 \\
\hline $\begin{array}{l}\text { bow education } \\
\text { grade (\%) }\end{array}$ & $16(34.8)$ & $18(21.4)$ & & 0.098 \\
\hline $\begin{array}{l}\text { Heavy work } \\
\text { during } \\
\text { pregnancy (\%) }\end{array}$ & $10(21.7)$ & $15(17.9)$ & & 0.591 \\
\hline $\begin{array}{l}\text { Smoking during } \\
\text { pregnancy }(\%)\end{array}$ & $4(8.7)$ & $6(7.1)$ & & 0.751 \\
\hline $\begin{array}{l}\text { Alcohol use } \\
\text { in the first- } \\
\text { trimester }(\%)\end{array}$ & $5(10.9)$ & $6(7.1)$ & & 0.465 \\
\hline $\begin{array}{l}\text { Febrile illness in } \\
\text { pregnancy }(\%)\end{array}$ & $3(6.5)$ & $0(0)$ & $\begin{array}{l}\text { Correction } \\
\chi^{2} \text { test }\end{array}$ & 0.079 \\
\hline
\end{tabular}

Table 2. Basic characteristics of patients with preterm birth or full-term delivery. Notes: T test, $\chi^{2}$ test and Correction $\chi^{2}$ test were applied to compare the difference of quantitative variables, qualitative variables (theoretical frequency $\geq 5$ ) and theoretical frequency $(1 \sim 5)$, respectively; ${ }^{*} P<0.05$ indicates a significant difference between PD and full-term delivery; ${ }^{\mathrm{a} C e r v i c a l}$ surgery indicates cervical conization or loop electrosurgical excision procedure cervical surgery; $b$, Low education grade indicates $\leq 12$ years compulsory education.

cooperation with the gynecologist's investigation $(\mathrm{n}=11)$ and uninformed absence in scheduled visiting to participating hospitals $(n=9)$ were also excluded from the present study. The remaining 130 patients were included in the study, and 46 (35.4\%) had spontaneous preterm birth before 37 weeks of gestation. 36 patients of which delivered at 32 to 36 weeks for $78.3 \%, 6$ patients delivered at 28 to 31 weeks for $13.0 \%$ and 4 patients delivered before 28 weeks for $8.7 \%$. There was no significant difference between the groups in terms of maternal age, parity, the rate of singleton or twin gestations, ratio of nulliparous vs. multiparous, cervical surgery, education grade, work or lifestyle or febrile illness during pregnancy $(P>0.05)$. However, cases in the preterm group had a significantly lower gestational age $(33.50 \mathrm{vs.} 39.20 \mathrm{~W})$ and lower birth weight $(2,573 \mathrm{vs} 3,628 \mathrm{~g})$ than those in the full-term group. Detailed demographic and clinical information are summarized in Table 2 and Fig. 2.

Distribution of test variables. Statistical evaluation of the test variables was performed by comparing their positive proportions between PD and full-term delivery. A higher proportion of the following eight variables was present in the PD group than that of the full-term delivery group $(P<0.05)$ : history of preterm delivery, prepregnancy BMI, the proportion of blue area, mean gray value, cervical dilatation, CL with singleton gestations, levels of fetal fibronectin and IL- $1 \beta$ in CVF. These were significant variables for evaluating PD in the present study. The difference between variables such as the use of tocolytic agents, CL with twin gestations and serum MIF was not significant $(P>0.05)$. Details are shown in Table 3 and Fig. 3.

Evaluation of the model. Eight variables were used to evaluate the prediction efficiency of the model. The results showed a prediction efficiency of $\geq 1 \times$ positive, $\geq 2 \times$ positives, $\geq 3 \times$ positives, and $\geq 4 \times$ positives that was higher than that of all negative, one positive, two positives and three positives. Furthermore, the accuracy rate of predicting PD showed an increased trend with increasing positive variables represented as $\geq 1 \times, \geq 2 \times, \geq 3 \times$ or $\geq 4 \times$. Conversely, the sensitivity showed a decreasing trend, while the specificity was still at relatively high levels. Based on the comprehensive evaluation of the accurate rate, sensitivity and specificity in different combinations of positive variables, the optimal cut-off point of the model was selected as " $\geq 2 \times$ positives" because of the relatively high characteristics in all aspects. Details are shown in Table 4 and Fig. 4.

\section{Discussion}

A two-step strategy of establishing and verifying a predictive model for preterm delivery in the second trimester of pregnancy was proposed in this study. First, a primary model of predicting PD was proposed using a combination of test variables originating from previous studies. In the primary model, ten variables from the eighteen previous studies were selected, including three dimensions in pregnant patients represented as epidemiological indices, morphology and tissue characteristics of the cervix and inflammatory cytokines in the CVF or serum. Subsequently, the model was evaluated using a non-probability sample of 130 pregnant patients. Generally, the results of validating the model showed eight significant variables for inclusion in the present analysis. The 
a

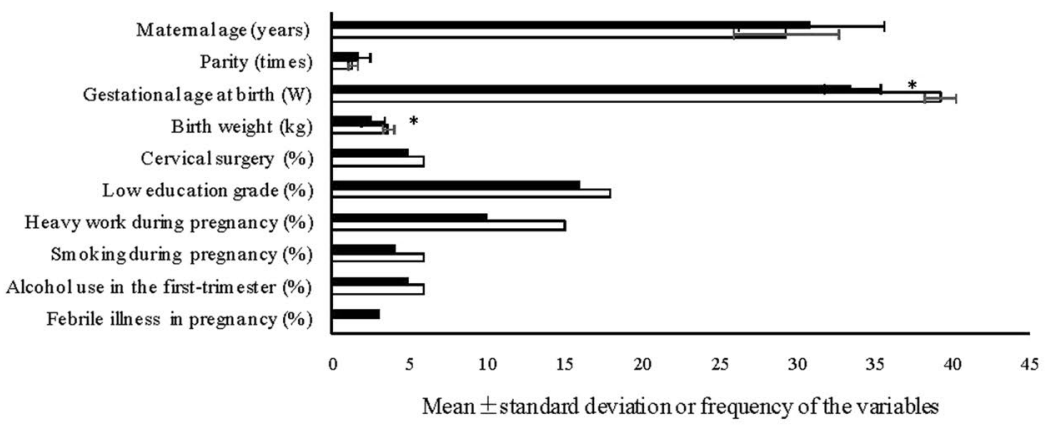

b

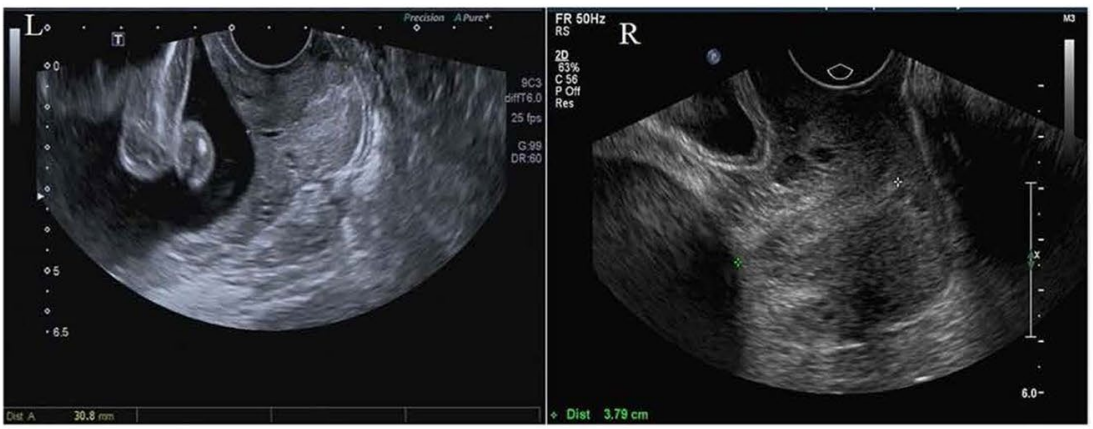

c

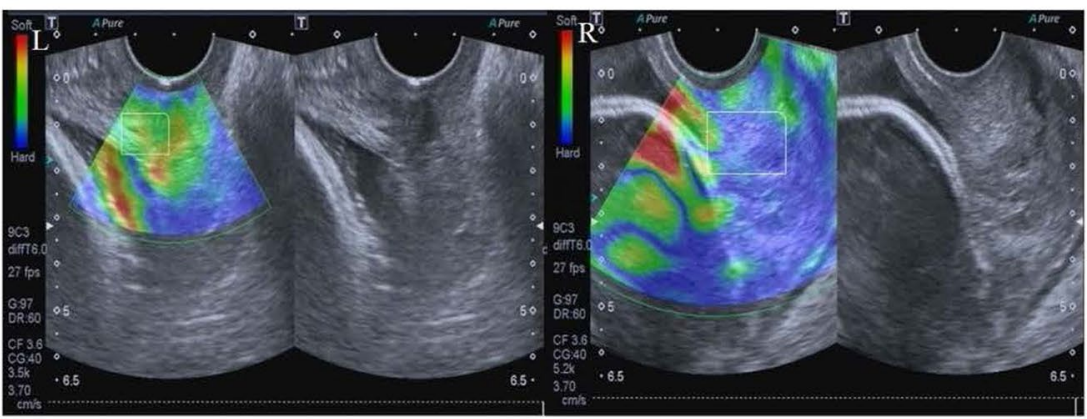

d

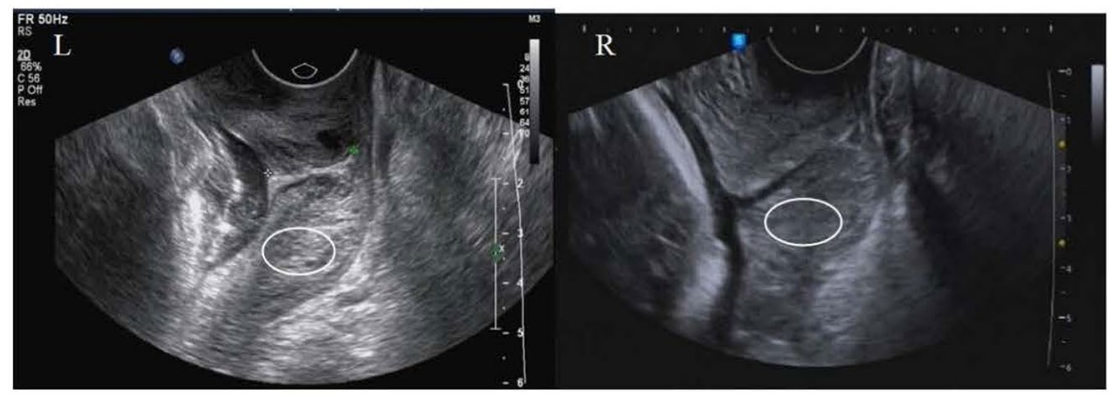

Figure 2. Characteristics of the pregnant patients. Note: (a) Basic characteristics of patients with preterm birth and full-term delivery. $* P<0.05$ indicates a significant difference between preterm delivery and full-term delivery; (b) Cervical length as determined by transvaginal ultrasound in pregnant patients. Left (L) shows a shortened cervix $(30.8 \mathrm{~mm})$, Right $(\mathrm{R})$ shows a normal cervical length $(37.9 \mathrm{~mm})$; (c) Blue area for cervical tissue as determined by sonoelastography in pregnant patients, the blue area indicates the stiffness of the cervical tissue. Left shows the percentage of blue area as an ROI (10.8\%) that indicates a soft elasticity of the cervix, Right shows the percentage of blue area as an ROI (29.7\%) that indicates relatively stiff cervical tissue; (d) Mean gray value of the sagittal transvaginal view in pregnant patients. Left shows a decreased echogenicity and grayscale value of 4.85, Right shows a normal echogenicity and grayscale value of 11.78 . 


\begin{tabular}{|c|c|c|c|c|c|}
\hline Test variables & $\begin{array}{l}\text { Value of } \\
\text { cut-off }\end{array}$ & $\mathbf{n}$ & $\begin{array}{l}\text { Preterm } \\
\text { delivery (\%) }\end{array}$ & $\begin{array}{l}\text { Full-term } \\
\text { delivery (\%) }\end{array}$ & $P$ value \\
\hline \multirow{2}{*}{$\begin{array}{l}\text { History of } \\
\text { preterm } \\
\text { delivery }\end{array}$} & Yes & 68 & $32(69.6)$ & $36(42.9)$ & \multirow{2}{*}{$0.004 * *$} \\
\hline & No & 62 & $14(30.4)$ & $48(57.1)$ & \\
\hline \multirow{2}{*}{$\begin{array}{l}\text { Prepregnancy } \\
\text { BMI }\left(\mathrm{kg} / \mathrm{m}^{2}\right)\end{array}$} & $<20$ & 43 & $28(60.9)$ & $26(30.9)$ & \multirow{2}{*}{$0.001 * *$} \\
\hline & $\geq 20$ & 87 & $18(39.1)$ & $58(69.1)$ & \\
\hline \multirow{2}{*}{$\begin{array}{l}\text { Use of tocolytic } \\
\text { agents }\end{array}$} & Yes & 61 & $25(54.3)$ & $39(46.4)$ & \multirow{2}{*}{0.388} \\
\hline & No & 69 & $21(45.7)$ & 45 (53.6) & \\
\hline \multirow{2}{*}{$\begin{array}{l}\text { Blue area in } \\
\text { ROI (\%) }\end{array}$} & $<11.0$ & 59 & $34(73.9)$ & $25(29.8)$ & \multirow{2}{*}{$0.000 * *$} \\
\hline & $\geq 11.0$ & 71 & $12(26.1)$ & $59(70.2)$ & \\
\hline \multirow{2}{*}{$\begin{array}{l}\text { Mean gray value } \\
\text { (amplitude) }\end{array}$} & $\leq 7.7$ & 70 & $33(71.7)$ & $38(45.2)$ & \multirow{2}{*}{$0.004 * *$} \\
\hline & $>7.7$ & 60 & $13(28.3)$ & $46(54.8)$ & \\
\hline \multirow{2}{*}{$\begin{array}{l}\text { Cervical } \\
\text { dilatation }(\mathrm{cm})\end{array}$} & $1 \sim 3$ & 67 & $30(65.2)$ & $37(44.0)$ & \multirow{2}{*}{$0.021^{*}$} \\
\hline & $\leq 1$ & 63 & $16(34.8)$ & $47(56.0)$ & \\
\hline \multirow{2}{*}{$\begin{array}{l}\text { CL-single } \\
\text { gestation }(\mathrm{mm})\end{array}$} & $\leq 30.9$ & 64 & $28(68.3)$ & $36(44.4)$ & \multirow{2}{*}{$0.013^{*}$} \\
\hline & $>30.9$ & 58 & $13(31.7)$ & $45(55.6)$ & \\
\hline \multirow{2}{*}{$\begin{array}{l}\text { CL-twin } \\
\text { gestations (mm) }\end{array}$} & $\leq 25.0$ & 5 & $3(-)$ & $2(-)$ & \multirow{2}{*}{$1.000^{\#}$} \\
\hline & $>25.0$ & 3 & $2(-)$ & $1(-)$ & \\
\hline \multirow{2}{*}{$\begin{array}{l}\text { aFetal } \\
\text { fibronectin (ng/ } \\
\mathrm{mL} \text { ) }\end{array}$} & $\geq 50$ & 62 & $27(62.8)$ & $35(41.7)$ & \multirow{2}{*}{$0.024^{*}$} \\
\hline & $<50$ & 65 & $16(37.2)$ & $49(58.3)$ & \\
\hline \multirow{2}{*}{$\begin{array}{l}\text { bSerum MIF } \\
(\mathrm{ng} / \mathrm{mL})\end{array}$} & $>9.2$ & 61 & $24(55.8)$ & $37(44.6)$ & \multirow{2}{*}{0.231} \\
\hline & $\leq 9.2$ & 65 & $19(44.2)$ & $46(55.4)$ & \\
\hline \multirow{2}{*}{${ }^{\mathrm{a}} \mathrm{IL}-1 \beta(\mathrm{pg} / \mathrm{mL})$} & $>55$ & 59 & $26(63.4)$ & $33(38.4)$ & \multirow{2}{*}{$0.008 * *$} \\
\hline & $\leq 55$ & 68 & $15(36.6)$ & $53(61.6)$ & \\
\hline
\end{tabular}

Table 3. Distribution of test variables between preterm delivery and full-term delivery. Notes: ROI, a rectangular region of interest, indicating the midsection region in the posterior wall of the cervix; $* P<0.05$ or $* * P<0.01$ for $\chi^{2}$ test; ${ }^{\#} P$ value for Fisher's exact test; a, 3 CVF samples missing; $b, 4$ specimens of serum missing.

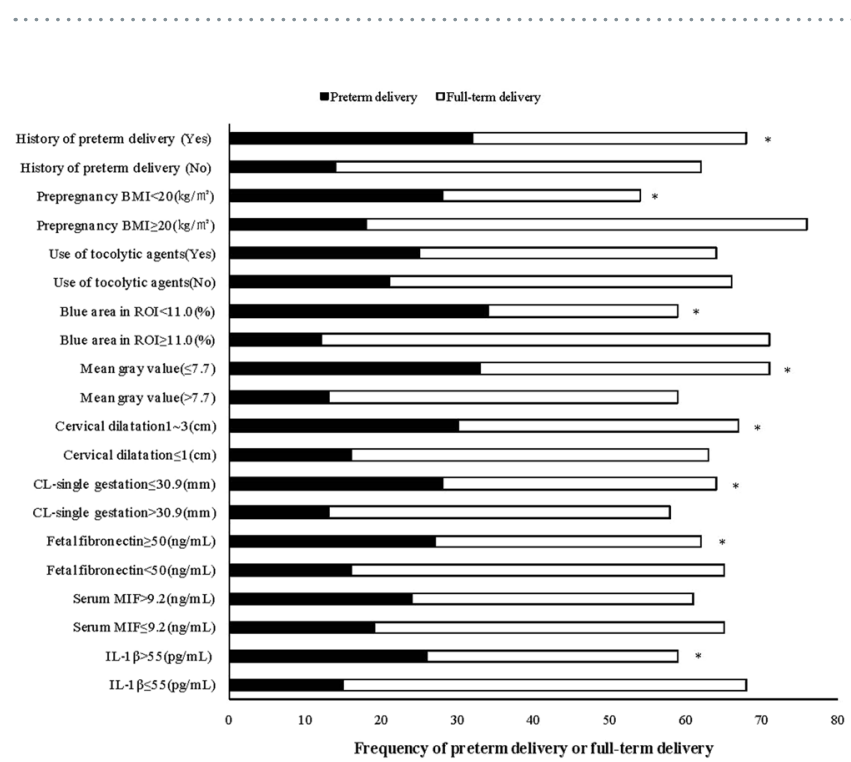

Figure 3. Distribution of test variables between preterm delivery and full-term delivery. Note: $* P<0.05$ indicates a significant difference between preterm delivery and full-term delivery; Cervical length with twin gestations was not shown owing to the small sample size.

variables of "use of tocolytic agents, serum MIF and CL in twin gestations" were excluded owing to the lack of statistical significance or small sample size. Furthermore, the combination analysis of positive variables showed that $\geq 2 \times$ positive variables existing in pregnant patients had a relatively high sensitivity $(82.6 \%)$, specificity $(88.1 \%)$ and accuracy rate $(79.2 \%)$ in predicting $\mathrm{PD}$, which is considered a cut-off point for predicting the occurrence of PD. Interestingly, all negative variables in the model had a high probability of association with full-term delivery, which is represented by an accuracy rate of $93.3 \%$. 


\begin{tabular}{|l|l|l|l|l|l|l|}
\hline $\begin{array}{l}\text { Combination of } \\
\text { variables }\end{array}$ & $\begin{array}{l}\text { Count of } \\
\text { occurring }\end{array}$ & $\begin{array}{l}\text { Preterm } \\
\text { delivery }(\mathbf{n})\end{array}$ & $\begin{array}{l}\text { Full-term } \\
\text { delivery }(\mathbf{n})\end{array}$ & $\begin{array}{l}\text { Sensitivity } \\
(\%)\end{array}$ & $\begin{array}{l}\text { Specificity } \\
(\%)\end{array}$ & $\begin{array}{l}\text { Accurate } \\
\text { rate (\%) }\end{array}$ \\
\hline All negative & 75 & 5 & 70 & 10.9 & 16.7 & $93.3^{\mathrm{a}}$ \\
\hline One positive & 7 & 3 & 4 & 6.5 & 95.2 & $42.9^{\mathrm{b}}$ \\
\hline Two positives & 32 & 24 & 8 & 52.2 & 90.5 & $75.0^{\mathrm{b}}$ \\
\hline Three positives & 11 & 9 & 2 & 19.6 & 97.6 & $81.8^{\mathrm{b}}$ \\
\hline$\geq 4 \times$ positives & 5 & 5 & 0 & 10.9 & 100.0 & $100.0^{\mathrm{b}}$ \\
\hline$\geq 3 \times$ positives & 16 & 14 & 2 & 30.4 & 97.6 & $87.5^{\mathrm{b}}$ \\
\hline$\geq 2 \times$ positives & 48 & 38 & 10 & 82.6 & 88.1 & $79.2^{\mathrm{b}}$ \\
\hline$\geq 1 \times$ positive & 55 & 41 & 14 & 89.1 & 83.3 & $74.5^{\mathrm{b}}$ \\
\hline
\end{tabular}

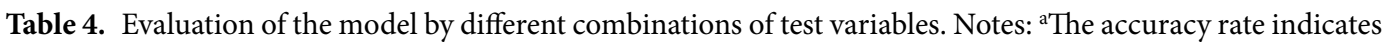
the percentage of full-term deliveries; ${ }^{b}$ The accuracy rate indicates the percentage of preterm deliveries.

a

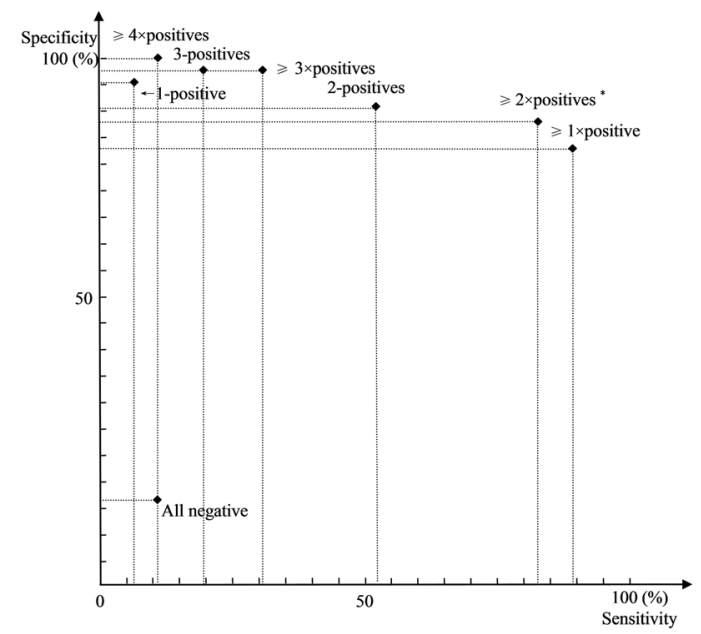

b

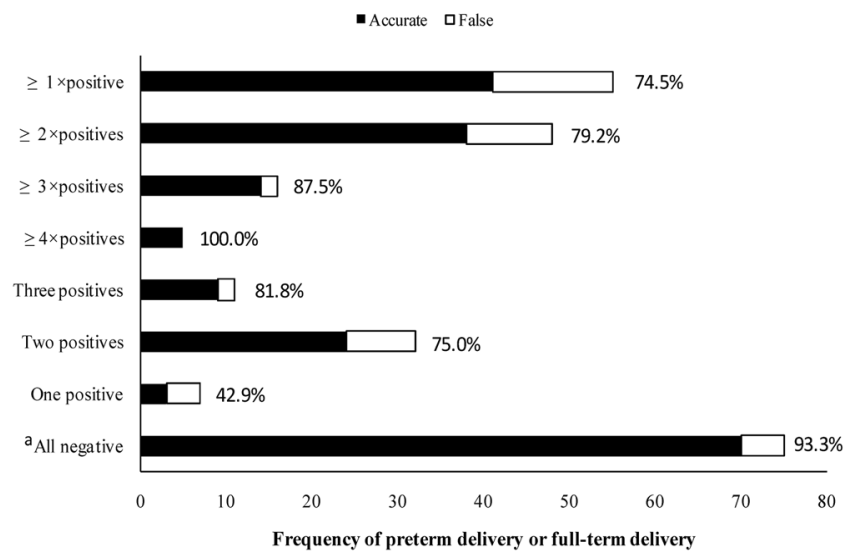

Figure 4. Evaluation of the model by sensitivity, specificity and accuracy. Note: (a) Sensitivity and specificity in single or combination of variables. The intersection of the abscissa and ordinate is represented as the characteristics of sensitivity and specificity in case of single variables or a combination of different variables. *Indicating the cutoff point of evaluating the present model; (b) Accuracy rate of the combination of different

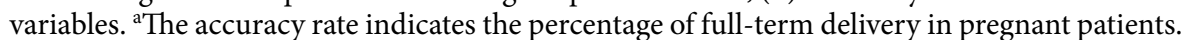

The significant association of the eight variables in the present model with PD occurrence was consistent with the conclusions from the previous studies. However, the inclusion of multiple combinations of these variables in the model showed a higher sensitivity and specificity than single or double combination of these variables in previous studies. For example, our results of $82.6 \%$ sensitivity in the combination of $\geq 2 \times$ positive variables was improved compared to a $33.3 \%$ sensitivity of a short cervix as a predictor of PD described by Lee et al..$^{18}$ and was 
also higher than the $63.8 \%$ or $43.9 \%$ sensitivity predicted by cervical dilatation or fetal fibronectin alone ${ }^{21}$. In addition, the finding that there was no significant association with PD and the "use of tocolytic agents or serum MIF" in our model was inconsistent with the previous studies by Pearce et al. ${ }^{6}$. The reason for this inconsistency may be attributed to differences in the study methods, sample collection, and geographical differences in patient. Based on the present result of predicting spontaneous PD during the second trimester of pregnancy in women in China, in our opinion, special attention should be given when a patient has two or more positive variables as defined in this study. In addition, some targeted interventions, such as the application of glucocorticoids for promoting fetal lung maturation or the administration of magnesium sulfate to protect the fetal central nervous system, should be performed if appropriate in the clinical situation. Of course, patients with only one positive variable for predicting PD cannot be ignored, as there was still a moderate accuracy rate of $42.9 \%$ with only one variable, so observation strict and regular evaluation of the development of the uterus and fetus is necessary to prevent the occurrence of PD.

In summary, we propose a model of predicting PD by introducing eight predictive indices originating from previous studies. The model showed an effective improvement in the sensitivity, specificity and predictive accuracy compared to previous models for predicting PD. In conclusion, the evaluation model of equal to or more than two positive variables provides a feasible reference for predicting PD in the second trimester of pregnancy in clinical patients. However, there are two limitations in this study. One limitation was the insufficient sample size for validation of the model because of other limitations of time, space and funding in the present study. The lack of sample size is particularly represented in the group with $\geq$ four positive variables. The other limitation was that genetic factors were not included in the present model because of a lack of reference literature. In a future study, we will expand the number of samples by including more pregnant patients from more hospitals, and we will proceed to evaluate the role of genetic factors in the occurrence of $\mathrm{PD}$, seeking to further improve the sensitivity, specificity and accuracy of the model and reduce false-positive results.

\section{Materials and Methods}

Establishment of the model. The study included two steps: establishment and verification of the model. When constructing the model, the test variables were selected discreetly according to the criteria of optimal sensitivity and specificity, which were determined based on previous multicenter or single-center studies of predicting PD in pregnant women from 1997 to 2016. Data involving sample size, cut-off values, sensitivity and specificity, from these studies was acquired using PubMed. As a result, ten variables from 17 original studies were included in the present model. The included variables were as follows: "history of PD, prepregnancy BMI, use of tocolytic agents, cervix tissue elasticity, densitometry of cervix, cervical dilatation, cervical length, fetal fibronectin in CVF, serum MIF, IL-1 $\beta$ in CVF". Cervical phosphorylated insulin-like growth factor binding protein-1 (phIGFBP-1) testing $^{34}$, plasma corticotrophin releasing hormone $(\mathrm{CRH})$ levels $^{35}$, placenta previa ${ }^{10}$ and bacterial vaginosis ${ }^{36}$ were excluded from the model because of the lower sensitivity or specificity than the included variables.

Design of the protocol. For the verification of the model, the designed prospective study of enrolling pregnant patients was approved from the Medical Ethics Committees in Xiangya Hospital, The Second Xiangya Hospital and Weihai municipal hospital. All experiments were carried out in accordance with the Declaration of Helsinki. A total of 186 pregnant patients who made scheduled visits to three participating hospitals from January 1, 2015 to March 1, 2016 were enrolled in accordance with approved guidelines. All participants were informed and signed a consent form presented by trained interviewers and their general epidemiologic and clinical data were recorded. Their gestational age varied from 17 to 28 weeks and 6 days as determined by the last menstrual period and ultrasonography in the first or early second trimester. Cervicovaginal fluid or serum specimens were collected and measurements from cervical ultrasonography were performed during a routine speculum examination by the managing gynecologist. Additionally, the following conditions were considered for exclusion at the time of enrollment: age $<15$ years, multiple gestations ( $\geq$ triple pregnancy), uterine or vaginal deformity, amniotic sac rupture, cervical dilatation $\geq 3 \mathrm{~cm}$, serious infection of the genital tract, frequent symptoms of threatened abortion such as vaginal bleeding or uterine contractions, and obstetric complications such as hypertension and diabetes mellitus. PD was defined as the spontaneous or non-indicated preterm delivery or preterm premature rupture of the fetal membranes prior to 37 weeks of gestation, and the correspondent data were collected during a follow-up period.

Measurement of ultrasound. Ultrasound scans of the uterine cervix were performed with a Premium Ultrasound System (5-9 MHz, Hi Vision Preirus, Hitachi Medical Systems, Wiesbaden, Germany). Measurements including cervical length via transvaginal ultrasonography, evaluation of the cervical tissue stiffness by sonoelastography and mean gray analysis were performed using quantitative ultrasound. The methods of detection and evaluation were determined by previous protocols ${ }^{22,24,28}$. Cervical length was defined as the distance between the internal and external os, which was measured in a sagittal plane of the cervix. Cervical tissue stiffness was represented by a color scale. Blue is indicative of stiff tissue, green represents average stiffness and red represents soft tissue. Furthermore, the proportion of blue area was calculated in a rectangular region of interest representing the posterior wall of the cervix. Acoustic densitometry (amplitude scale) of a region of constant size (10 Diameter Circle) in the cervical tissue was also measured using the US System (Philips Medical Systems, Hamburg, Germany). Each examination was repeated three times by two different investigators.

Detection of cytokines. A total of $10 \mathrm{~mL}$ of cervicovaginal lavage fluid was collected, and the centrifugal supernatants were frozen at $-70^{\circ} \mathrm{C}$ for detecting the concentrations of IL- $1 \beta$ or fetal fibronectin (fFN) as previously described ${ }^{14,21,33}$. An IL-1 $\beta$ human enzyme-linked immunosorbent assay (ELISA) Kit (Thermo Fisher Scientific Inc, California, USA) and fFN Enzyme Immunoassay Kit (Adeza Biomedical Corporation, Sunnyvale, 
Calif) were used, and a positive result of IL- $1 \beta$ or fFN was defined as $>55 \mathrm{pg} / \mathrm{mL}$ or $\geq 50 \mathrm{ng} / \mathrm{mL}$, respectively. In addition, serum MIF was detected using a sandwich ELISA assay as described by Pearce et al. ${ }^{30,31}$, and an anti-MIF polyclonal antibody (Abcam, Cambridge, USA) was used with a positive result defined as $>9.2 \mathrm{ng} / \mathrm{mL}$. All cytokines were determined repeatedly three times by each separate sample according to the manufacturer's instructions.

Evaluation of prediction efficiency. Positive or negative results of the test variables were calculated according to their corresponding cut-off values in each pregnant patient, and the difference in the distribution of positive variables between the PD group and the full-term delivery group was analyzed using the $\chi^{2}$ test with $P<0.05$. Furthermore, sensitivity, specificity and accuracy rates of single or different combinations of positive variables were also calculated for evaluating the efficiency of predicting PD. Then, the prediction efficiency of more than one or several positive results including $2 \times, 3 \times$ or $4 \times$ were also evaluated. Ultimately, prediction efficiency and cut-off point of the established model was evaluated by a comprehensive comparison of sensitivity, specificity and accuracy rates among different combinations of positive variables.

Data availability. All data generated or analyzed during this study are present in the article; Additional data related to this paper may be requested from the authors.

\section{References}

1. Beck, S. et al. The worldwide incidence of preterm birth: a systematic review of maternal mortality and morbidity. Bulletin of the World Health Organization 88, 31-38, doi:10.2471/blt.08.062554 (2010).

2. Torchin, H. \& Ancel, P. Y. Epidemiology and risk factors of preterm birth. J Gynecol Obstet Biol Reprod (Paris), doi:10.1016/j. jgyn.2016.09.013 (2016).

3. Matthews, T. J. \& MacDorman, M. F. Infant mortality statistics from the 2010 period linked birth/infant death data set. National vital statistics reports: from the Centers for Disease Control and Prevention, National Center for Health Statistics, National Vital Statistics System 62, 1-26 (2013).

4. Zou, L. et al. Preterm birth and neonatal mortality in China in 2011. International journal of gynaecology and obstetrics: the official organ of the International Federation of Gynaecology and Obstetrics 127, 243-247, doi:10.1016/j.ijgo.2014.06.018 (2014).

5. Cui, H. et al. Trendency analysis of infant mortality rate due to premature birth or low birth weight in China from 1996 to 2013 . Zhonghua yu fang yi xue za zhi [Chinese journal of preventive medicine] 49, 161 (2015).

6. Owen, J., Goldenberg, R. L., Davis, R. O., Kirk, K. A. \& Copper, R. L. Evaluation of a risk scoring system as a predictor of preterm birth in an indigent population. American journal of obstetrics and gynecology 163, 873-879 (1990).

7. Torchin, H., Ancel, P. Y., Jarreau, P. H. \& Goffinet, F. [Epidemiology of preterm birth: Prevalence, recent trends, short- and long-term outcomes]. J Gynecol Obstet Biol Reprod (Paris) 44, 723-731, doi:10.1016/j.jgyn.2015.06.010 (2015).

8. Cnattingius, S. et al. Maternal obesity and risk of preterm delivery. Jama 309, 2362-2370, doi:10.1001/jama.2013.6295 (2013).

9. Gyamf, I. B. C. Maternal obesity is an independent risk factor for spontaneous extremely preterm delivery. Evid Based Med 19, 71, doi:10.1136/eb-2013-101477 (2014).

10. Erez, O. et al. Early preterm delivery due to placenta previa is an independent risk factor for a subsequent spontaneous preterm birth. BMC pregnancy and childbirth 12, 82, doi:10.1186/1471-2393-12-82 (2012).

11. Albayrak, E. et al. Is evaluation of placenta with real-time sonoelastography during the second trimester of pregnancy an effective method for the assessment of spontaneous preterm birth risk? Clinical Imaging 40, 926-930, doi:10.1016/j.clinimag.2016.04.006 (2016).

12. Vrachnis, N. et al. The Janus face of maternal serum relaxin: a facilitator of birth, might it also induce preterm birth? J Matern Fetal Neonatal Med 28, 2187-2191, doi:10.3109/14767058.2014.981804 (2015).

13. Kekki, M. et al. Insulin-like growth factor-binding protein-1 in cervical secretion as a predictor of preterm delivery. Acta Obstet Gynecol Scand 80, 546-551 (2001).

14. Genc, M. R. et al. A disproportionate increase in IL-1beta over IL-1ra in the cervicovaginal secretions of pregnant women with altered vaginal microflora correlates with preterm birth. American journal of obstetrics and gynecology 190, 1191-1197, doi:10.1016/j. ajog.2003.11.007 (2004).

15. Liong, S. et al. Prediction of spontaneous preterm labour in at-risk pregnant women. Reproduction 146, 335-345, doi:10.1530/rep13-0175 (2013)

16. Liong, S. et al. New biomarkers for the prediction of spontaneous preterm labour in symptomatic pregnant women: a comparison with fetal fibronectin. Bjog-an International Journal of Obstetrics and Gynaecology 122, 370-379, doi:10.1111/1471-0528.12993 (2015).

17. Bruijn, M. M. et al. The predictive value of quantitative fibronectin testing in combination with cervical length measurement in symptomatic women. American journal of obstetrics and gynecology 215, 793.e791-793.e798, doi:10.1016/j.ajog.2016.08.012 (2016).

18. Lee, K. A. et al. A model for prediction of spontaneous preterm birth in asymptomatic women. J Womens Health (Larchmt) 20, 1825-1831, doi:10.1089/jwh.2011.2729 (2011).

19. Facco, F. L., Nash, K. \& Grobman, W. A. Are women who have had a preterm singleton delivery at increased risk of preterm birth in a subsequent twin pregnancy? American journal of perinatology 25, 657-659, doi:10.1055/s-0028-1090592 (2008).

20. Hendler, I. et al. The Preterm Prediction Study: association between maternal body mass index and spontaneous and indicated preterm birth. American journal of obstetrics and gynecology 192, 882-886, doi:10.1016/j.ajog.2004.09.021 (2005).

21. Peaceman, A. M. et al. Fetal fibronectin as a predictor of preterm birth in patients with symptoms: a multicenter trial. American journal of obstetrics and gynecology 177, 13-18 (1997).

22. von Schoning, D. et al. Cervical sonoelastography for improving prediction of preterm birth compared with cervical length measurement and fetal fibronectin test. Journal of perinatal medicine 43, 531-536, doi:10.1515/jpm-2014-0356 (2015).

23. Wozniak, S. et al. Elastography in predicting preterm delivery in asymptomatic, low-risk women: a prospective observational study. BMC pregnancy and childbirth 14,238, doi:10.1186/1471-2393-14-238 (2014).

24. Tekesin, I. et al. Evaluation of quantitative ultrasound tissue characterization of the cervix and cervical length in the prediction of premature delivery for patients with spontaneous preterm labor. American journal of obstetrics and gynecology 189, 532-539 (2003).

25. Tekesin, I., Wallwiener, D. \& Schmidt, S. The value of quantitative ultrasound tissue characterization of the cervix and rapid fetal fibronectin in predicting preterm delivery. Journal of perinatal medicine 33, 383-391, doi:10.1515/jpm.2005.070 (2005).

26. Tekesin, I., Meyer-Wittkopf, M., Sierra, F. \& Schmidt, S. Quantitative ultrasonic tissue characterization of the cervix - A new predictor for prematurity? Zeitschrift fur Geburtshilfe und Neonatologie 206, 88-93, doi:10.1055/s-2002-32648 (2002).

27. Dilek, T. U. et al. Progressive cervical length changes versus single cervical length measurement by transvaginal ultrasound for prediction of preterm delivery. Gynecologic and obstetric investigation 64, 175-179, doi:10.1159/000106486 (2007). 
28. Ozkaya, E. et al. Myometrial elasticity determined by elastosonography to predict preterm labor. The journal of maternal-fetal \& neonatal medicine: the official journal of the European Association of Perinatal Medicine, the Federation of Asia and Oceania Perinatal Societies, the International Society of Perinatal Obstet 27, 1518-1521, doi:10.3109/14767058.2013.863864 (2014).

29. Fuchs, F. \& Senat, M. V. Multiple gestations and preterm birth. Semin Fetal Neonatal Med 21, 113-120, doi:10.1016/j.siny.2015.12.010 (2016).

30. Pearce, B. D. et al. Serum macrophage migration inhibitory factor in the prediction of preterm delivery. American journal of obstetrics and gynecology 199, 46.e41-46, doi:10.1016/j.ajog.2007.11.066 (2008).

31. Pearce, B. D. et al. Interrelationship of cytokines, hypothalamic-pituitary-adrenal axis hormones, and psychosocial variables in the prediction of preterm birth. Gynecologic and obstetric investigation 70, 40-46, doi:10.1159/000284949 (2010).

32. Kedzierska-Markowicz, A., Krekora, M., Biesiada, L., Glowacka, E. \& Krasomski, G. Evaluation of the correlation between IL-1beta, IL-8, IFN-gamma cytokine concentration in cervico-vaginal fluid and the risk of preterm delivery. Ginekologia polska 86, 821-826 (2015).

33. Imai, M. et al. Significance of fetal fibronectin and cytokine measurement in the cervicovaginal secretions of women at term in predicting term labor and post-term pregnancy. European journal of obstetrics, gynecology, and reproductive biology 97, 53-58 (2001).

34. Conde-Agudelo, A. \& Romero, R. Cervical phosphorylated insulin-like growth factor binding protein-1 test for the prediction of preterm birth: a systematic review and metaanalysis. American journal of obstetrics and gynecology 214, 57-73, doi:10.1016/j. ajog.2015.06.060 (2016).

35. Sibai, B. et al. Plasma CRH measurement at 16 to 20 weeks' gestation does not predict preterm delivery in women at high-risk for preterm delivery. American journal of obstetrics and gynecology 193, 1181-1186, doi:10.1016/j.ajog.2005.06.036 (2005).

36. Klebanoff, M. A. et al. Is bacterial vaginosis a stronger risk factor for preterm birth when it is diagnosed earlier in gestation? American journal of obstetrics and gynecology 192, 470-477, doi:10.1016/j.ajog.2004.07.017 (2005).

\section{Acknowledgements}

We would like to thank Xiangya Hospital, the Second Xiangya Hospital and Weihai municipal hospital for providing the data convenience. This study was sponsored by the Hunan Province Natural Science Foundation (2016JJ6106).

\section{Author Contributions}

Design of the study and collection of clinical data were performed by Y.Z., G.P.,G.T., and X.Q., S.X. is responsible for the integrity of the data and the accuracy of the data analysis.

\section{Additional Information}

Competing Interests: The authors declare that they have no competing interests.

Publisher's note: Springer Nature remains neutral with regard to jurisdictional claims in published maps and institutional affiliations.

(c) (i) Open Access This article is licensed under a Creative Commons Attribution 4.0 International License, which permits use, sharing, adaptation, distribution and reproduction in any medium or format, as long as you give appropriate credit to the original author(s) and the source, provide a link to the Creative Commons license, and indicate if changes were made. The images or other third party material in this article are included in the article's Creative Commons license, unless indicated otherwise in a credit line to the material. If material is not included in the article's Creative Commons license and your intended use is not permitted by statutory regulation or exceeds the permitted use, you will need to obtain permission directly from the copyright holder. To view a copy of this license, visit http://creativecommons.org/licenses/by/4.0/.

(C) The Author(s) 2017 